\title{
Laparoscopic Sleeve Gastrectomy and Its Effects on Hypertension
}

\author{
Kourosh Sarkhosh ${ }^{\mathrm{a}, \mathrm{c}}$, Michael Lai ${ }^{\mathrm{a}, \mathrm{c}}$, Richdeep Gilla, \\ Daniel W. Birch ${ }^{\mathrm{a}, \mathrm{b}}$, Shahzeer Karmalia, b, c, d
}

\begin{abstract}
Obesity is a common disease affecting adults and children worldwide. Bariatric surgery currently is the only effective procedure resulting a sustainable and long-term weight loss. Laparoscopic sleeve gastrectomy (LSG) is a relatively new but effective procedure. The purpose of this review is to evaluate the current evidence on the effects of LSG on hypertension.
\end{abstract}

Keywords: Morbid obesity; Obesity surgery; Sleeve gastrectomy; Hypertension

\section{Introduction}

The prevalence of obesity has continued to rise over the last

Manuscript accepted for publication February 14, 2012

${ }^{a}$ Center for the Advancement of Minimally Invasive Surgery (CAMIS), Royal Alexandra Hospital, 10240 Kingsway, Edmonton, Alberta, T5H 3V9, Canada

${ }^{\mathrm{b}}$ Department of Surgery, University of Alberta, Edmonton, Alberta, Canada

${ }^{\mathrm{c}}$ These authors contributed equally to this work

${ }^{\mathrm{d}}$ Corresponding author: Shahzeer Karmali, Center for the Advancement of Minimally Invasive Surgery (CAMIS), Royal Alexandra Hospital, 10240 Kingsway, Edmonton, Alberta, T5H 3V9, Canada.Email: shahzeer@ualberta.ca

doi: $10.4021 / \mathrm{jcs} 26 \mathrm{w}$ few decades. Over 300 million adults are considered clinically obese worldwide [1]. In Canada an estimated $60 \%$ of the population is considered overweight [2]. Obesity is defined as a BMI $\geq 30 \mathrm{~kg} / \mathrm{m}^{2}$, and morbid obesity is defined as a BMI $\geq 40 \mathrm{~kg} / \mathrm{m}^{2}$.

Obesity is a known risk factor for development of several comorbidities. Some significant obesity-related conditions include diabetes mellitus, hypertension, sleep apnea, hyperlipidemia, gastroesophageal reflex disease, and degenerative joint disease [3]. It is estimated that 1 in 10 premature deaths are directly attributable to obesity in Canadian adults aged 20 - 64 [4]. Obesity is one of the largest and most important epidemics facing Canadians today.

\section{Bariatric Surgery}

Bariatric surgery is currently the most effective evidencebased method to obtain long-term weight loss in severely obese patients [5]. Laparoscopic sleeve gastrectomy (LSG) is a new bariatric procedure introduced in the 1990's for the management of severely obese patients. It was initially used as the first step to a two-stage approach to biliopancreatic diversion with duodenal switch (BPD-DS) [6], but has been recently shown to be an effective single procedure [7]. LSG is characterized as a restrictive procedure and functions to mechanically limit food intake. Furthermore, it is thought that LSG may decrease appetite stimulation by resecting the portion of gastric fundus responsible for producing ghrelin [8].

\section{Obesity and Hypertension}

Obesity and the presence of adipose tissue have been associated with increased blood pressure. The precise pathophysiology to the development of hypertension in obese patients is currently unknown. However, there are several factors involved in obesity-related hypertension including physiologic, genetic and environmental factors. Hypertension is also a known component of the metabolic syndrome, which consists of centripetal obesity, dyslipidemia, impaired glucose 
tolerance and insulin resistance [9]. It has been postulated that in the obese, activation of the renin-angiotensin-aldosterone system (RAAS) and sympathetic nervous system may contribute to high blood pressure [10]. Estimates of up to $70 \%$ of hypertension in adults may be directly caused by adiposity [11]. It has also been postulated that obesity-related hypertension may be in part due to increased renal sodium retention and impaired pressure naturesis [12]. Recent evidence has suggested that adipocytes releasing neuroendocrine hormones may impact arterial pressure [9]. Adiposerelated causes of hypertension may thus be reduced with weight loss.

There have been many recent studies that have shown improvement or resolution of hypertension following LSG. A multi-center study by Sanchez et al [13] found that hypertension was improved in $63 \%$ of LSG patients. Hutter et al [14] conducted a prospective study on 944 patients and reported that $68 \%$ had improvement or resolution of hypertension at one year follow up. In another cohort study, Basso et al [15] found that out of 100 high-risk super obese patients with a mean BMI of $54.4 \mathrm{~kg} / \mathrm{m}^{2}$ had complete resolution of their hypertension in $62 \%$ of cases. A long-term study done by D'Hondt et al reported that $90.9 \%$ of LSG patients had improvement or resolution of hypertension 5 years post-operatively [16]. A systematic review by Sarkhosh et al [17] found that out of 3997 patients, $75 \%$ had improvement or resolution of their hypertension and 58\% had complete resolution of hypertension following sleeve gastrectomy. In a meta-analysis done by Buchwald et al [18], improvement or complete resolution of hypertension was seen $70.8 \%, 87.2 \%$, $85.4 \%$ and $75.1 \%$ of patients undergoing gastric banding, gastric bypass, gastroplasty and biliopancreatic diversion/ duodenal switch respectively.

\section{Conclusion}

In conclusion, there has been promising evidence of the beneficial effects of laparoscopic sleeve gastrectomy (LSG) on hypertension in obese patients. It has been found in many studies that sleeve gastrectomy results in resolution or improvement in hypertension in the majority of patients. LSG is therefore an effective surgical option for weight loss as well and improvement of associated comorbidities of obesity. Further studies are needed to evaluate the effect of bariatric surgery and sleeve gastrectomy on comorbidities on a long-term basis.

\section{References}

1. Ahima RS. Digging deeper into obesity. J Clin Invest. 2011;121(6):2076-2079.

2. Adult obesity prevalence in Canada and the United
States. In: Canadian health measures survey. http:// www.statcan.gc.ca/dailyquotidien/110302/dq110302ceng.htm. Accessed July 2011.

3. Karmali S, Schauer P, Birch D, Sharma AM, Sherman V. Laparoscopic sleeve gastrectomy: an innovative new tool in the battle against the obesity epidemic in Canada. Can J Surg. 2010;53(2):126-132.

4. Lau DC, Douketis JD, Morrison KM, Hramiak IM, Sharma AM, Ur E, Obesity Canada Clinical Practice Guidelines Expert P. 2006 Canadian clinical practice guidelines on the management and prevention of obesity in adults and children [summary]. CMAJ. 2007;176(8):S113.

5. Gill RS, Birch DW, Shi X, Sharma AM, Karmali S. Sleeve gastrectomy and type 2 diabetes mellitus: a systematic review. Surg Obes Relat Dis. 2010;6(6):707713.

6. Hess DS, Hess DW. Biliopancreatic diversion with a duodenal switch. Obes Surg. 1998;8(3):267-282.

7. Moon Han S, Kim WW, Oh JH. Results of laparoscopic sleeve gastrectomy (LSG) at 1 year in morbidly obese Korean patients. Obes Surg. 2005;15(10):1469-1475.

8. Karamanakos SN, Vagenas K, Kalfarentzos F, Alexandrides TK. Weight loss, appetite suppression, and changes in fasting and postprandial ghrelin and peptide-YY levels after Roux-en-Y gastric bypass and sleeve gastrectomy: a prospective, double blind study. Ann Surg. 2008;247(3):401-407.

9. Kotchen TA. Obesity-related hypertension: epidemiology, pathophysiology, and clinical management. Am J Hypertens. 2010;23(11):1170-1178.

10. Narkiewicz K. Obesity and hypertension--the issue is more complex than we thought. Nephrol Dial Transplant. 2006;21(2):264-267.

11. Must A, Spadano J, Coakley EH, Field AE, Colditz G, Dietz WH. The disease burden associated with overweight and obesity. JAMA. 1999;282(16):1523-1529.

12. Hall JE. The kidney, hypertension, and obesity. Hypertension. 2003;41(3 Pt 2):625-633.

13. Sanchez-Santos R, Masdevall C, Baltasar A, MartinezBlazquez C, Garcia Ruiz de Gordejuela A, Ponsi E, Sanchez-Pernaute A, et al. Short- and mid-term outcomes of sleeve gastrectomy for morbid obesity: the experience of the Spanish National Registry. Obes Surg. 2009;19(9):1203-1210.

14. Hutter MM, Schirmer BD, Jones DB, Ko CY, Cohen ME, Merkow RP, Nguyen NT. First report from the American College of Surgeons Bariatric Surgery Center Network: laparoscopic sleeve gastrectomy has morbidity and effectiveness positioned between the band and the bypass. Ann Surg. 2011;254(3):410-420; discussion 420-412.

15. Basso N, Casella G, Rizzello M, Abbatini F, Soricelli E, Alessandri G, Maglio C, et al. Laparoscopic sleeve 
gastrectomy as first stage or definitive intent in 300 consecutive cases. Surg Endosc. 2011;25(2):444-449.

16. D'Hondt M, Vanneste S, Pottel H, et al. Laparoscopic sleeve gastrectomy as a single-stage procedure for the treatment of morbid obesity and the resulting quality of life, resolution of comorbidities, food tolerance, and 6-year weight loss. Surg Endosc 2006; 20:859-63.
17. Sarkhosh K, Birch DW, Shi X, Gill RS, Karmali S. The Impact of Sleeve Gastrectomy on Hypertension: A Systematic Review. Obes Surg. 2012.

18. Buchwald H, Avidor Y, Braunwald E, Jensen MD, Pories W, Fahrbach K, Schoelles K. Bariatric surgery: a systematic review and meta-analysis. JAMA. 2004;292(14):1724-1737. 